\title{
To study medical students' perspective on rising violence against doctors. Do they consider obstetrics and gynecology a risky branch?
}

\author{
Reena Sood $^{1 *}$, Gurmeet Singh ${ }^{2}$, Parvinder Arora ${ }^{1}$
}

\begin{abstract}
${ }^{1}$ Department of Obstetrics and Gynecology, ${ }^{2}$ Department of Pediatrics, Sri Guru Ram Das Institute of Medical Sciences and Research, Amritsar, Punjab, India
\end{abstract}

Received: 01 July 2017

Accepted: 07 July 2017

\section{*Correspondence:}

Dr. Reena Sood,

E-mail: dr.reenasood@gmail.com

Copyright: () the author(s), publisher and licensee Medip Academy. This is an open-access article distributed under the terms of the Creative Commons Attribution Non-Commercial License, which permits unrestricted non-commercial use, distribution, and reproduction in any medium, provided the original work is properly cited.

\begin{abstract}
Background: In recent years, there has been an epidemic of violence against health professional in many nations including India. The Indian Medical Association (IMA) has reported that $75 \%$ of doctors have faced physical or verbal violence during their lifetime. The objective of present study was to evaluate the medical student perspective on rising violence against doctors.

Methods: This is a cross sectional questionnaire based study carried out at Sri Guru Ram Das Institute of medical Sciences and Research Amritsar. Undergraduate medical students from second year onwards, interns and postgraduate students of the institution were included in the study. Data was compiled and statistically analysed.

Results: Total 497 medical students participated in the study. Among participants $327(65.8 \%)$ were undergraduates, $106(21.3 \%)$ were interns, $64(12.9 \%)$ were postgraduate students $97.18 \%$ of students said that they were aware of rising incidents of violence against doctors. while $96 \%$ of participants said that they were concerned about the problem. For $86.1 \%$ students source of information of these incidents was social media. $82.5 \%$ participants said that doctors are at higher risk of being victim of violence than other profession. $89.1 \%$ of participants who had said that doctors are at higher risk of being victims of violence than other professions have said yes to the question that doctors need to be trained in martial arts. $70.2 \%$ said that these incidences would affect their future carrier choices. $60.8 \%$ Students said that certain specialties are more prone to receive violence than others. In response to an open-ended question which specialties are more prone, $83.6 \%$ participants had written surgical branches and obstetrics and gynecology.

Conclusions: The study indicates that they find certain specialties more-risky and their inclination towards nonsurgical branches for post-graduation.
\end{abstract}

Keywords: Medical students, Obstetrics and gynecology, Violence

\section{INTRODUCTION}

Violence is defined as behaviour involving physical force intended to hurt, damage, or kill someone or something. The Occupational Safety and Health Administration (OSHA) a department of the United States Department of Labor defines workplace violence as any act or threat of physical violence, harassment, intimidation, or other threatening disruptive behaviour that occurs at the work site. It ranges from threats and verbal abuse to physical assaults and even homicide. ${ }^{1}$

According to WHO Health workers are at high risk of violence all over the world. Between $8 \%$ and $38 \%$ of health workers suffer physical violence at some point in their careers. Many more are threatened or exposed to verbal aggression. Most violence is perpetrated by patients and visitors. ${ }^{2}$ 
In recent years there has been an epidemic of violence against health professional in many nations including India. The Indian Medical Association (IMA) has reported that $75 \%$ of doctors have faced physical or verbal violence during their lifetime. ${ }^{3}$ In this study, we evaluated the medical student's perspective on rising violence against doctors and its effect on their future carrier choices in medical fields. The objective of present study was to evaluate the medical student's perspective on rising violence against doctors.

\section{METHODS}

This is a crossectional questionnaire based study carried out at Sri Guru Ram Das Institute of medical Sciences and Research Amritsar. prior to study permission was taken from institute ethical committee. Undergraduate medical students from second year onwards, interns and post-graduate students of the institution were included in the study. Those who willingly participated in the study were given a questionnaire. Participants were asked not to disclose their identity. They were given 25 minutes of time to fill the questionnaire. Results of NEET PG 2017 Second counselling result were analysed in relation to the speciality chosen for postgraduation by students. ${ }^{4}$

\section{Statistical analysis}

Data was compiled and statistically analysed using software SPSS version 20.0.

\section{RESULTS}

Total 497 medical students participated in the study. 177 $(35.6 \%)$ were males and were $320(64.4 \%)$ were females. $73(14.7 \%)$ participants were from rural and $424(85.3 \%)$ were from urban areas. 152(30.6\%) participants belonged to a medical background and $345(69.2 \%)$ belonged to a non-medico family.

Table 1: Demographic profile.

\begin{tabular}{|lllll|}
\hline \multirow{2}{*}{ Sex } & \multicolumn{2}{l}{ Male } & \multicolumn{3}{l|}{ Female } \\
& 177 & $35.6 \%$ & 320 & $64.4 \%$ \\
\hline \multirow{2}{*}{ Residence } & Rural & \multicolumn{3}{l|}{ Urban } \\
\cline { 2 - 5 } & 73 & $14.7 \%$ & 424 & $85.3 \%$ \\
\hline $\begin{array}{l}\text { Family } \\
\text { background }\end{array}$ & \multicolumn{2}{l}{ Medico } & \multicolumn{2}{l}{ Non-medico } \\
\cline { 2 - 5 } & 152 & $30.5 \%$ & 345 & $69.2 \%$ \\
\hline
\end{tabular}

Among participants $327(65.8 \%)$ were undergraduates, $106(21.3 \%)$ were interns, $64(12.9 \%)$ were postgraduate students.

Table 2: Distribution of subjects.

\begin{tabular}{|lll|}
\hline Student category & N & $\%$ age \\
\hline Undergraduates & 327 & $65.8 \%$ \\
\hline Interns & 106 & $21.3 \%$ \\
\hline Post Graduates & 64 & $12.9 \%$ \\
\hline
\end{tabular}

$155(31.2 \%)$ students said they chose the profession because of parent's suggestion, 338 (68.0\%) participants said they chose profession because of self-interest, 71 (14.3\%) participants said they chose the profession because they wanted to serve humanity and only 29 $(5.8 \%)$ participants said they chose it for being lucrative profession.

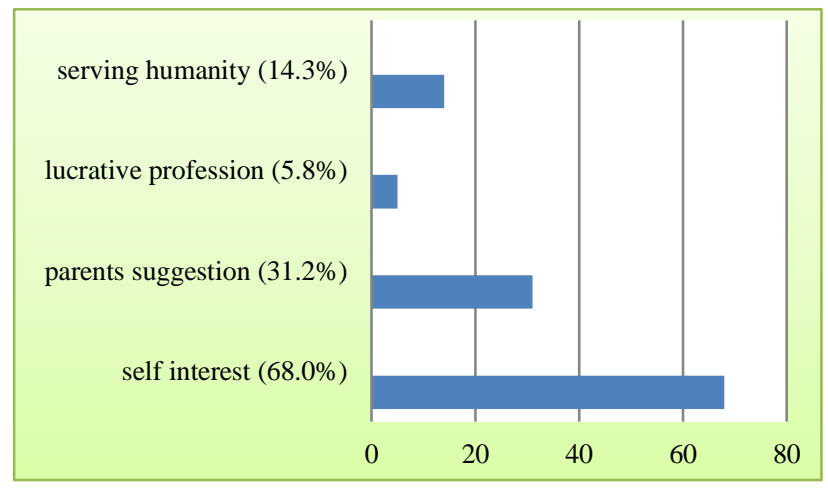

Figure 1: Reason for choosing the profession.

$202(40.6 \%)$ participants said that the Hippocratic oath still holds relevance in modern times, 152 (30.6\%) answered no to this question. Rest 143 (28.6\%) said they can not say whether oath is relavant today or not.

Table 3: Correlation between students' response to two different questions.

\begin{tabular}{|llllll|}
\hline & \multicolumn{4}{c}{$\begin{array}{l}\text { Are doctors at } \\
\text { higher risk of being } \\
\text { victims of violence }\end{array}$} & Total \\
\begin{tabular}{|l} 
Do doctors need \\
special training \\
as martial arts
\end{tabular} & & Yes & No & $\begin{array}{l}\text { Can't } \\
\text { say }\end{array}$ & \\
\hline & Yes & 245 & 4 & 26 & 275 \\
\cline { 2 - 6 } & No & 78 & 20 & 19 & 117 \\
\cline { 2 - 6 } & $\begin{array}{l}\text { Can't } \\
\text { say }\end{array}$ & 87 & 6 & 12 & 105 \\
\hline Total & & 410 & 30 & 57 & 497 \\
\hline
\end{tabular}

Pearson Chi square value 41.58. $\mathrm{df}=4 . \mathrm{p}$ value is 0.000 (significant)

$483(97.18 \%)$ of students said that they were aware of rising incidents of violence against doctors. while $96 \%$ of participants said that they were concerned about the problem. For $86.1 \%$ students source of information of these incidents was social media, $41.4 \%$ said source of information was electronic media and $23.7 \%$ said it was print media. $82.5 \%$ participants said that doctors are at higher risk of being victim of violence than other profession. $89.1 \%$ of participants who had said that doctors are at higher risk of being victims of violence than other professions have said yes to the question that doctors need to be trained in martial arts.

$80.1 \%$ participants believed that media misinformation was one of the reasons for rise in these incidents. 


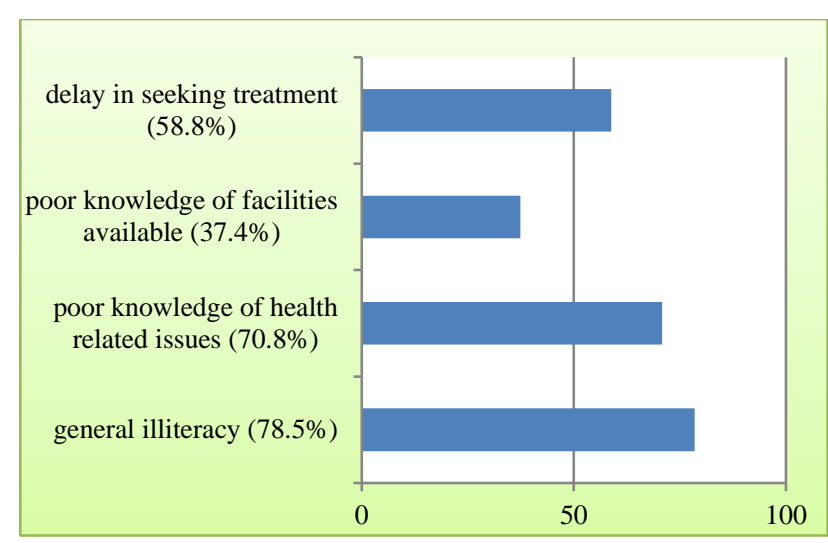

Figure 2: Patient related factors for violence.

$70.2 \%$ said that these incidences would affect their future carrier choices. $60.8 \%$ Students said that certain specialities are more prone to receive violence than others. In response to an open-ended question which specialities are more prone, $83.6 \%$ participants had written surgical branches and obstetrics and gynecology.

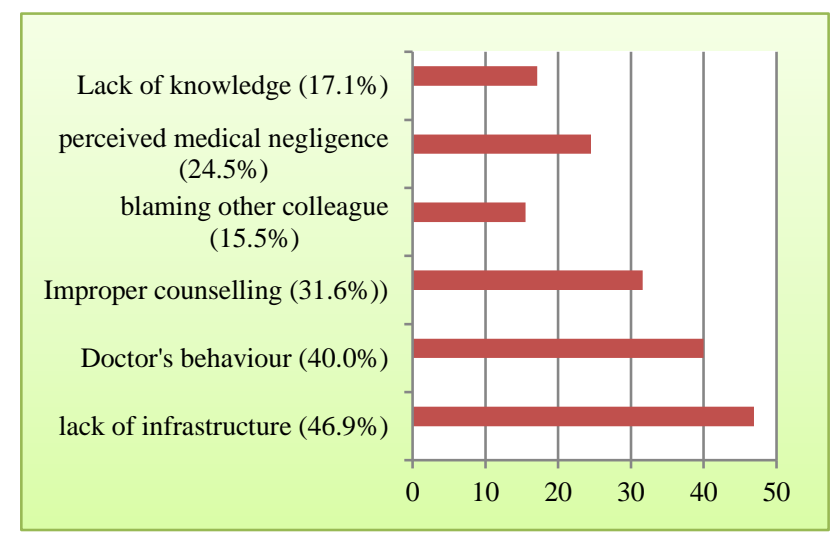

Figure 3: Doctor related factors for violence.

We analysed the results of NEET PG 2017 Second counselling result 4 . Choice of branch for post-graduation showed a trend of inclination towards non-surgical branches. Counselling results showed that among first 500 AIR ranks $26 \%$ of students opted for General medicine, $21.6 \%$ students opted for Radiodiagnosis, $12.8 \%$ chose paediatrics, $5.8 \%$ opted for othopedics, $5.4 \%$ opted for general surgery and only $2.6 \%$ opted for obstetrics and gynecology. These results prove lesser preference of students toward surgery and obstetrics and gynecology, which maximum no of students have answered as more prone for violence.

The students who have chosen the profession on their parents' suggestion out of them only $25.9 \%$ have said that they will suggest the same profession to their siblings. $41.2 \%$ of the students who have taken the profession on their own interest have said yes for the question that they will suggest the same profession to their siblings. So significant number of those who chose field because of self-interest still find it being worthy of recommending to siblings, while who chose it because of parental suggestion think otherwise.

$62.8 \%$ participants said that triggering factor for violence was death of the patient. $77.9 \%$ of the participants said that training and orientation of the doctors needs to be improved. $33.6 \%$ students said that doctors in government hospitals are more prone to receive violence. $21.1 \%$ believed that doctors in medical college are more prone, $10.3 \%$ believed same for corporate hospitals. $40.8 \%$ of students said that they will not recommend same profession to their siblings.

\section{DISCUSSION}

In India tradition traces the genesis of medicine from a mythical through a semi mythical to a historical beginning. Dhanwantri, who is a great celebrity in Ayurveda is regarded as a part of Vishnu and a disciple of Shiva. ${ }^{5}$ In past Doctors enjoyed good reputation and respect. But today scenario has changed. There is a new epidemic invading medical profession across the entire globe. Doctors are being threatened, attacked verbally as well as physically. Many of those who are attacked or threatened experience anger, fear, anxiety, self-blame, and loss of confidence. ${ }^{6}$ In China, the practise of attacking hospitals and healthcare staff is rather rampant. Due to increasing violence in recent years against medical staff that endangers the personal safety of medical practitioners, the number of Chinese medical school applicants has decreased greatly. ${ }^{7}$

Present study is a questionnaire based study on medical students. Total 497 medical students participated in the study. Majority of medical students (69.2\%) are from non-medico background. Maximum students $(68.0 \%)$ have chosen field because of self-interest, $14.3 \%$ chose the profession because they wanted to serve humanity and only 5.8\% participants said they chose it for being lucrative profession. This indicate that maximum students will become doctors because they wanted so. Significant number of those who chose field because of self-interest still find it being worthy of recommending to siblings, while who chose it because of parental suggestion think otherwise. $96 \%$ of participants said that they were concerned about the problem of violence in their profession. For $86.1 \%$ students source of information of violence incidents was social media, this again indicates inclination of students towards social media. $82.5 \%$ participants said that doctors are at higher risk of being victim of violence than other profession. So significant percentage of our future doctors is aware and concerned about issue. $89.1 \%$ of participants who had said that doctors are at higher risk of being victims of violence than other professions have said yes to the question that doctors need to be trained in martial arts. $80.1 \%$ participants believed that media misinformation was one of the reasons for rise in these incidents. These figures highlight the factor that when these students start their professional carriers they will have a guarded approach 
towards their patient, which is bound to have an impact on their relations with the patient.

In response to an open-ended question which specialities are more prone, $83.6 \%$ participants believed that surgical branches and obstetrics and gynecology were more prone specialities. Analysis of the results of NEET PG 2017 Second counselling result for first 500 AIR ranks proves the liking of students for non-surgical branches. Only $5.4 \%$ students have opted for general surgery and only $2.6 \%$ have opted for obstetrics and gynecology. So, students are preferring general medicine and radiodiagnosis over surgery and obstetrics and gynecology. These results are consistent with the opinion given by students in present study as $83.6 \%$ participants believed that surgical branches and obstetrics and gynecology were more prone specialities for violence.

This is in contrast to an earlier study done in Nepal in 2015 where results indicated preference of the students for postgraduation to be clinical surgical $(50.9 \%)$, clinical medical (45.3\%), and basic medical (3.9\%) sciences were in descending order. The most preferred specialty among male students was clinical surgical sciences $(56.3 \%)$, and among female students, it was clinical medical sciences $(53.6 \%){ }^{8}$

Due to rising violence incidents strikes and protests by medical doctors have become a common global phenomenon. In india many times in different states junior doctors have gone on strike because of this issue, their chief demand being that their security at the hospitals should be ensured. In a study done among doctors working in a tertiary care hospital in Delhi it was found that higher proportion of doctors from the department of surgery experienced workplace violence compared to other departments..$^{9}$

A 2016 study carried out in a tertiary care hospital in New Delhi reported that over $40 \%$ of resident doctors were exposed to violence in the workplace in the past 12 months. Junior doctors face the most violence. They are posted as first responders in emergency rooms but most of them are inexperienced in handling patient queries. Relatives of patients also do not treat them as doctors with experience, resulting in conflict situations. ${ }^{10}$

The problem is multi-factorial in origin. Lately, Indian society is experiencing a growing awareness regarding patient's rights. This trend is clearly discernible from the recent spurt in litigation concerning medical professional or establishment liability, claiming redressal for the suffering caused due to medical negligence, vitiated consent, and breach of confidentiality arising out of the doctor-patient relationship. ${ }^{11}$ Trust in the doctor-patient relationship has taken a beating over the last few decades. The hospitals offering subsidized medical care are swamped with patients and their attendants This may impart a perception of neglect to the patient and leave him/her only partially satisfied. Ineffective communication or delay in attending to a patient can easily drive them over the edge. ${ }^{12}$

Other reason for this is misperception and unreasonable expectations among patients and relatives regarding healthcare and adverse events. In a country like India where illiteracy is high, or in Western countries where malpractice suits are prevalent, such unpredictable adverse events are not accepted by patients' families and can result in misperceptions and anger. This leads to attacks on doctors physically or in a court of law. ${ }^{13}$ Taking measures for controlling violence against doctors, Now Indian Medical Association is all set to launch an online initiative that persuades its members to report assault cases of doctors on duty the initiative is still under the process of finalization. ${ }^{14}$ There is a need for more efforts to end this menace. Media needs to play a more balanced role. Doctor patient relation needs more to be improved. A doctor should be close to patients' family to build trust. More stringent laws should be there.

\section{CONCLUSION}

Violence against doctors is a growing concern for medical fraternity. Students are future doctors and their perception of the issue is important. The study indicates that they find certain specialities more-risky and their inclination towards non-surgical branches for postgraduation.

\section{Funding: No funding sources \\ Conflict of interest: None declared}

Ethical approval: The study was approved by the Institutional Ethics Committee

\section{REFERENCES}

1. Workplace violence. Occupational safety and health administration. Available at https://www.osha.gov/SLTC/workplaceviolence/ Accessed on 10 June 2017

2. WHO. Violence and injury prevention. Violence against health workers. Available at http://www.who.int/violence_injury_prevention/viol ence/workplace/en/. Accessed on 10 June 2017.

3. Over $75 \%$ of doctors have faced violence at work, study finds - Times of India [Internet]. The Times of India. 2017 [cited 28 June 2017]. Available at http://timesofindia.indiatimes.com/india/Over-75-ofdoctors-have-faced-violence-at-work-studyfinds/article

4. Neet PG Counselling 2017. Available at http://www.medicine.careers360.com/articles/neetpg-counselling.

5. Ramachandran CK. Physicians and surgeons in ancient India. Anc Sci Life. 1981;1(2):69-71.

6. Morrison J, Lantos J, Levinson W. Aggression and violence directed toward physicians. J General Inter Med. 1998;13(8):556-61. 
7. Xu XY, Gao W, Zhang AJ, Huang J, Cui M, Zhao $\mathrm{W}$. What has shaken the determination of medical students to become a doctor? Chinese Med J. 2017;130(8):1001.

8. Jha RK, Paudel KR, Shah DK, Sah AK, Basnet S, Sah P et al. Subject preferences of first- and secondyear medical students for their future specialization at Chitwan Medical College and Teaching Hospital, Chitwan, Nepal Bangladash; a questionnaire-based study. Adv Med Edu Pract. 2015;6:609.

9. Anand T, Grover S, Kumar R, Kumar M, Ingle GK. Workplace violence against resident doctors in a tertiary care hospital in Delhi. Natl Med J India. 2016;29(6):344.

10. Sharma D. Rising violence against health workers in India. The Lancet. 2017;389(10080):1685.

11. Rao JS. Medical negligence liability under the consumer protection act: A review of judicial perspective. Indian J Urol. 2009;25(3):361.

12. Ambesh P. Violence against doctors in the Indian subcontinent: A rising bane. Indian Heart J. 2016;68(5):749-50.
13. Supe A. Violence against doctors cannot be tolerated - The BMJ [Internet]. Blogs.bmj.com. 2017 [cited 16 June 2017]. Available at http://blogs.bmj.com/bmj/2017/03/29/avinash-supeviolence-against-doctors-cannot-be-tolerated/

14. IMA to launch online registry to compile cases of violence against doctors - ET HealthWorld [Internet]. ETHealthworld.com. 2017 [cited 27 June 2017] Available http://health.economictimes.indiatimes.com/news/ind ustry/ima-to-launch-online-registry-to-compilecases-of-violence-against-doctors/580078563.

Cite this article as: Sood R, Singh G, Arora P. To study medical student's perspective on rising violence against doctors. Do they consider obstetrics and gynecology a risky branch?. Int J Reprod Contracept Obstet Gynecol 2017;6:3314-8. 